\title{
Diffuse Cutaneous Mastocytosis
}

National Cancer Institute

\section{Source}

National Cancer Institute. Diffuse Cutaneous Mastocytosis. NCI Thesaurus. Code C3218.

A variant of cutaneous mastocytosis which is seen almost exclusively in children. (WHO,

2001) -- 2003 